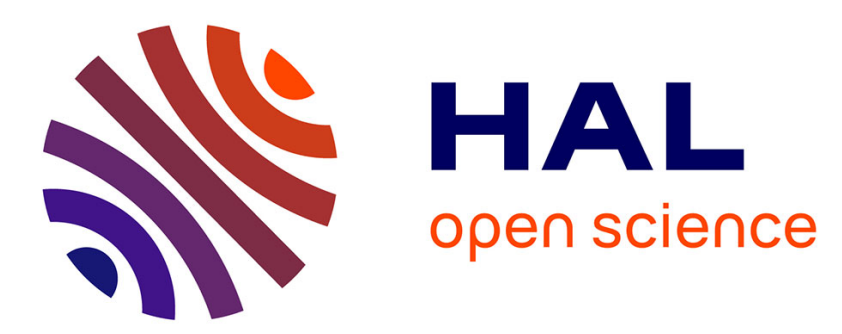

\title{
Modeling local growth control decisions in a multi-city case: Do spatial interactions and lobbying efforts matter?
}

\author{
Katharina Schone, Wilfried Koch, Catherine Baumont
}

\section{- To cite this version:}

Katharina Schone, Wilfried Koch, Catherine Baumont. Modeling local growth control decisions in a multi-city case: Do spatial interactions and lobbying efforts matter?. Public Choice, 2013, 154 (1-2), pp.95-117. halshs-01228450

\section{HAL Id: halshs-01228450 \\ https://shs.hal.science/halshs-01228450}

Submitted on 11 Dec 2015

HAL is a multi-disciplinary open access archive for the deposit and dissemination of scientific research documents, whether they are published or not. The documents may come from teaching and research institutions in France or abroad, or from public or private research centers.
L'archive ouverte pluridisciplinaire HAL, est destinée au dépôt et à la diffusion de documents scientifiques de niveau recherche, publiés ou non, émanant des établissements d'enseignement et de recherche français ou étrangers, des laboratoires publics ou privés. 


\title{
Modeling local growth control decisions in a multi-city case: \\ Do spatial interactions and lobbying efforts matter?
}

\section{Katharina Schone • Wilfried Koch • Catherine Baumont}

\begin{abstract}
Our article analyzes the determinants of local growth control decisions, which are modeled as the result of a political struggle between different groups of voters and organized lobbies. We show that under specific hypotheses, a higher homeownership rate can induce lower levels of controls. Considering residential choices as endogenous to growth control policies, the local decisions to control growth become strategically interdependent. Assuming imperfect mobility, we show that a spatial econometric specification can be directly derived from our theoretical model. Our empirical analysis concerning the determinants of the "taxe locale d'équipement", a French local development tax, is thus naturally based on spatial econometrics. Its results confirm the major predictions of our model.
\end{abstract}

Keywords land use regulation; growth control; lobbying; spatial econometrics JEL Classification R52, C31, D7, H7

\footnotetext{
K. Schone $(\bowtie)$

AgroParisTech-ENGREF, LEF, 14 rue Girardet, 54042 Nancy Cedex, France

e-mail: katharina.schone@ nancy-engref.inra.fr

W. Koch

Université du Québéc à Montréal, P.O. Box 8888, Station Centre-ville, Montreal, Quebec H3C3P8, Canada

C. Baumont

University of Burgundy, LEG, 2 boulevard Gabriel, BP 26611, 21066 Dijon Cedex, France
} 


\section{Introduction}

In most industrialized countries, local governments have extensive powers to manage and control their own geographic and demographic development, including a wide array of land-related policies such as zoning rules, land taxation, impact fees and urban growth boundaries, sometimes grouped under the term "growth controls". These powers and their widespread use are generally justified as necessary corrections to market failure. Growth controls are meant to limit the negative externalities related to urban growth (pollution, congestion, etc.), to prevent urban sprawl and to guarantee a fair distribution of the fiscal burden generated by urban growth. However, at the same time, growth controls also have a considerable impact on land and housing prices. An extensive empirical literature currently exists on this question, which, to a large extent, concludes that growth controls raise housing prices and lower the value of undeveloped land (see Fischel 1990 or Quigley and Rosenthal 2005 for a review of results).

In view of these considerable financial consequences, it seems quite plausible that local landowners and homeowners will try to influence growth control decisions. Therefore, the decision to control the development of a municipality is probably not best described as being taken by a "benevolent dictator" with the unique intention to maximize social welfare. On the contrary, it seems, instead, to be the result of a political struggle between different land-related lobbies, each trying to influence local decision makers. Theoretical models that describe growth control decisions as the result of a struggle for influence between different interest groups include Brueckner (1995), Richer (1995), or more recently, Glaeser et al. (2005) and Hilber and Robert-Nicoud (2007).

The major opponents in this political struggle are the owners of developed land, who benefit from control-induced rising real estate values, and the owners of undeveloped land, logically opposed to every kind of measure that limits the possibility of developing their 
property. At first glance, the owners of undeveloped land, who generally represent only a small percentage of the population, could be expected to have little influence on the local political decision process. However, according to the still popular hypothesis first put forth by Molotch (1976) and Logan and Molotch (1987), they gain influence by forming an "urban growth machine" with members of the local business elite such as local employers, banks or building companies that all have a natural interest in local expansionism. As a matter of course, building companies want to maximize the number of new constructions, which simultaneously raises profits for local banks that lend money to new homebuyers. Local employers support the growth machine because high construction rates help to keep housing prices down, which in turn permits them to pay their workers less.

This pro-growth pressure group finds itself confronted with the owners of already developed land, who either live in the house or apartment they own or who rent it out and act as landlords. Owner-occupiers and landlords both favor stringent growth controls, but it is still an open question as to which of these two subgroups benefits the most from growth controls and exerts the strongest influence on local political decisions.

The general view holds that local politics tend to be dominated by resident homeowners trying to defend their local quality of life and, at the same time, the value of their house. The fact that the house they own generally represents their biggest single asset and that they do not have any possibility of spreading the risks turns them into "homevoters", a term coined by Fischel (2001). Brueckner and Lai (1996) and Hilber and Robert-Nicoud (2007), on the contrary, identify the homeowners that act as landlords as the main driving force behind restrictive growth control policies. According to their analysis, owner-occupiers can be imagined as paying rent to themselves and, for this reason, a control-induced rent escalation actually provides them with no benefit. In contrast, "absentee" homeowners (that is, homeowners acting as landlords and living elsewhere) clearly gain from rent increases and thus favor even more stringent growth controls than resident homeowners. Following this line 
of reasoning, a higher homeownership rate could be associated with less stringent growth controls for the simple reason that higher homeownership rates imply lower renter rates, which in turn means that fewer landlords have a stake in local political decision-making.

Compared to the numerous studies on the effects of growth controls, empirical evidence on their determinants is still scarce, and the existing analyses almost exclusively focus on North American cities. The existing studies generally conclude that a municipality's growth control choice is influenced by prior population growth and given population density (see, for example, Bates and Santerre 1994; Evenson and Wheaton 2003; Glaeser and Ward 2009). Most studies also find that controls are more stringent in municipalities with a higher income level (Pogodzinski and Sass 1994; Evenson and Wheaton 2003; McDonald and McMillen 2004).

Nevertheless, no consensus has emerged from the existing literature regarding the influence of the homeownership rate. The results obtained by Dubin et al. (1992) point to a positive relationship between the homeownership rate and the stringency of controls. In contrast, Clingermayer (1993), Pogodzinski and Sass (1994) and Glaeser and Ward (2009) have found a negative relationship, and the results of Brueckner (1998) and Gordon (2009) indicate no significant influence of the percentage of homeowners in the local population.

The influence of pressure groups other than resident homeowners has only rarely been analyzed. Lubell et al. (2005) and Glaeser and Ward (2009) reported a significant negative relationship between restrictive growth policies and the local importance of the construction sector, which can be interpreted as a proxy for the lobbying efforts undertaken by the members of an "urban growth machine".

Drawing on the aforementioned theoretical and empirical literature, our article makes two contributions to the analysis of the determinants of local growth control decisions. First of all, we present a theoretical model that clearly represents the political struggle regarding this decision. Our model distinguishes two different cases, a first one in which the sole 
interest of local political decision makers lies in getting re-elected, and a second one in which, besides seeking re-election, politicians also respond to the promises and pressures of organized lobbying groups. Our model clearly shows that the link between the homeownership rate and the stringency of growth controls is positive in the first case, whereas it may become negative in the second case.

Second, our analysis takes account of the fact that a city's decision to set up growth controls generally creates spillover effects and increases demand for land and housing in other cities. ${ }^{1}$ Local growth control choices will therefore be spatially interdependent and cities will engage in strategic interactions. These strategic interactions were first integrated into a model on growth control decisions by Brueckner (1995) and Helsley and Strange (1995), but without modeling their spatial pattern. The only empirical test so far was provided by Brueckner (1998), who, using spatial econometric techniques, showed that cities in California tended to impose more stringent growth controls when neighboring cities were doing so. Although spatial econometrics have proven useful for the empirical analysis of strategic interactions between governments (Brueckner 2003; Revelli 2005), filling the gap between theoretical models and spatial econometric specifications remains a challenge (Behrens and Thisse 2007). In the present article, we extend the analysis of Helsley and Strange (1995) and establish the equilibrium for the case of multiple interacting cities. Moreover, contrary to the existing literature, we integrate the fundamentally geographic nature of interdependencies and present a spatial econometric specification that is directly derived from the theoretical model. We thus attempt to make a first step in bridging the gap between theoretical modeling and spatial econometric specifications.

The remainder of the article is divided into four parts. The next section introduces the theoretical model. Considering strategic interactions in prices, we model the internal as well

\footnotetext{
${ }^{1}$ Empirical evidence for spillover effects to adjacent jurisdictions is given by Pollakowski and Wachter (1990) and Cho and Linneman (1993).
} 
as the external forces shaping a city's growth control decisions and derive a theoretically motivated estimation equation that reveals spatial interactions. Our empirical test, presented in Section 3, is thus naturally based on spatial econometric tools. Making use of standard as well as Bayesian spatial econometric methods, we analyze the factors influencing the decision of municipalities to raise the "taxe locale d'équipement" (referred to hereafter as the TLE), a French local development tax that can be regarded as a price measure to control growth. To our knowledge, this is the first study of the determinants of growth control choices within the French context. The results of our empirical analysis are presented in Section 4. Section 5 contains some concluding remarks and suggestions for future empirical research.

\section{Theoretical model}

Extending the work of Helsley and Strange (1995) to the multi-city case, we consider the strategic adoption of growth control policies in a closed system of cities. Municipalities aim at controlling urban extension through development fees that raise the settlement cost in the city and that have an impact on population shifts across cities. Growth control choices are modeled as the result of a political struggle between different land-related interest groups and are considered as being interdependent due to their impact on residential location. Households move to another city when they perceive a utility difference at the expense of their actual city of residence, but their perception of what happens in other cities is assumed to be limited. This imperfect mobility due to limited perception is taken into account by the cities' reaction functions derived from our model.

\subsection{Intra-urban equilibrium}

The urban setting. We consider a system of monocentric cities, $j \in\{0,1, \ldots, J\}$, occupying linear strips of land. Each city has a single central business district (CBD), located in 0, that 
concentrates all employment. One unit of land at each distance from the CBD is devoted to residential occupation. Thus, every residential location in a city is characterized by its distance $x$ from the CBD. Each city $j$ extends up to a maximum distance of $\bar{x}_{j}$.

The total population of city $j$, referred to as $n_{j}$, is divided into two groups designated by $k$ : renters $(k=0)$ and homeowners $(k=1)$. Like Brueckner and Lai (1996), we suppose that renters are mobile between cities, whereas homeowners are immobile. Homeowners are distributed equally amongst the cities of the urban system, each city hosting $n^{1}$ homeowners. Hence, their total number is $N^{1}=(J+1) n^{1}$. Since renters are mobile between cities, $n_{j}^{0}$, the number of renters living in city $j$, is variable. The total number of renters can be expressed as $N^{0}=\sum_{j=0}^{J} n_{j}^{0}$.

All inhabitants of city $j$ work in the CBD, where homeowners earn an income of $y_{j}^{1}$ and renters an income of $y_{j}^{0}$, where $y_{j}^{0}<y_{j}^{1}$. Land consumption is inelastic. Each homeowner consumes one unit of land, and each renter $\alpha<1$ units. The physical size of the city is thus related to its population size by $\bar{x}_{j}=\alpha n_{j}^{0}+n^{1}$.

Household behavior. The utility level of a city's inhabitants depends on their land consumption, their consumption of a numeraire, as well as on the quality of life $Q_{j}$ in their city of residence. Due to congestion or other disamenity effects, the quality of life in a city is assumed to decline with the size of the city:

$$
Q_{j}=-\beta n_{j}
$$


where $\beta \geq 0$ represents the externality parameter. ${ }^{2}$ An individual living at distance $x$ from the CBD has to incur commuting costs equal to $t x$. A renter's budget constraint can thus be written:

$$
y_{j}^{0}=c_{j}^{0}+t x+\alpha r_{j}^{0}(x)
$$

and a homeowner's budget constraint is:

$$
y_{j}^{1}+\gamma R_{j}=c_{j}^{1}+t x+r_{j}^{1}(x)
$$

where $r_{j}^{0}(x)$ represents the rent that a renter living at distance $x$ from the CBD has to pay for one unit of land, and $r_{j}^{1}(x)$ the land rent of a homeowner. $\gamma R_{j}$ is the homeowner's rental income. Each homeowner receives a share $\gamma$ of $R_{j}$, the total land rents realized in city $j$. Like Helsley and Strange (1995), we assume, for the sake of simplicity, that the utility functions are additively separable and that utility is transferable. The utility functions of a homeowner or a renter can then be respectively expressed as:

$$
\begin{aligned}
& u_{j}^{1}=y_{j}^{1}+\gamma R_{j}-t x-\beta n_{j}-r_{j}^{1}(x) \\
& u_{j}^{0}=y_{j}^{0}-t x-\beta n_{j}-\alpha r_{j}^{0}(x)
\end{aligned}
$$

Intra-urban equilibrium. An intra-urban equilibrium is attained when no household wants to change its location anymore, i.e., when any two homeowners, living at different distances $x^{A}$ and $x^{B}$ from the CBD, obtain the same utility level:

$$
r_{j}^{1}\left(x^{B}\right)-r_{j}^{1}\left(x^{A}\right)=t\left(x^{A}-x^{B}\right)
$$

and, likewise, any two renters:

$$
r_{j}^{0}\left(x^{B}\right)-r_{j}^{0}\left(x^{A}\right)=\frac{t}{\alpha}\left(x^{A}-x^{B}\right)
$$

\footnotetext{
${ }^{2}$ Under a more realistic assumption, residents' utility would rise with population size until the city reaches its optimal size $n^{*}$, and would decline only once population grows beyond this critical size: $Q_{j}=-\beta\left|n_{j}-n^{n}\right|$. However, using this assumption instead of equation [1] does not crucially modify our results as long as the population externality is not too strong compared to commuting costs. In order to avoid further complicating notations, we therefore prefer this simpler hypothesis.
} 
Two homeowners (or two renters) living in the same city but at different distances from the CBD attain the same utility level if the difference between their respective transport costs is exactly compensated for by the difference between the land rents they pay. Since renters consume less land than homeowners, the renters' land rent declines more rapidly with distance from the CBD than the homeowners' rent function.

Given that the two groups of inhabitants are characterized by different levels of income and land consumption, each group will occupy a specific part of the city, the members of one group living in the central part (between the CBD and $\hat{x}_{j}$ ) and the members of the other one living in the outer part (between $\hat{x}_{j}$ and $\bar{x}_{j}$ ). At the distance $\hat{x}_{j}$, which indicates the boundary between both groups, their respective land rents have to be identical. Following [6] and [7], the renters outbid the homeowners at all distances $x<\hat{x}$, whereas the homeowners' land rent is higher than that of the renters for all distances $x>\hat{x}$. Thus, the renters live in the central part of the city and the homeowners in the outer part.

If the opportunity cost of urban land is zero and the city does not implement any policies in order to control growth, it naturally extends until $r\left(\bar{x}_{j}\right)=0$. In this case, in intraurban equilibrium, the land rents of the two groups can be written as:

$$
\begin{aligned}
& r_{j}^{1}(x)=t\left(n^{1}+\alpha n_{j}^{0}\right)-t x \\
& r_{j}^{0}(x)=t\left(n^{1}+n_{j}^{0}\right)-\frac{t}{\alpha} x
\end{aligned}
$$

\subsection{Growth controls}

If local decision-makers adopt measures to control growth, they prevent the city from extending until $r\left(\bar{x}_{j}\right)=0 .^{3}$ Thus, a city that actively controls its own growth is characterized

\footnotetext{
${ }^{3}$ Since the model is static in nature, we do not actually analyze growth control policies, i.e., instruments restricting a city's growth but, instead, policies that restrict its size. Since the conclusions of the analysis are
} 
by a positive land rent at the boundary of the city. According to Helsley and Strange (1995), it is possible to distinguish growth control measures that directly limit population size through land use regulations and "price control" measures that indirectly influence population and city size by acting on land prices. While Brueckner (1998) concentrates on the first of these measures, we are interested in the second one.

We define a price control as an entry fee $p_{j}$ to the city, i.e., a minimum land rent for everyone who wants to live in city $j$. Thus, land rent at the boundary becomes $r\left(\bar{x}_{j}\right)=p_{j}$, and the land rent functions of homeowners and renters can now be expressed as:

$$
\begin{aligned}
& r_{j}^{1}(x)=t\left(n^{1}+\alpha n_{j}^{0}\right)-t x+p_{j} \\
& r_{j}^{0}(x)=t\left(n^{1}+n_{j}^{0}\right)-\frac{t}{\alpha} x+p_{j}
\end{aligned}
$$

Substituting [10] in [4] and [11] in [5], we obtain utility in city $j$ as a function of the characteristics of the city:

$$
\begin{aligned}
& u_{j}^{1}=y_{j}^{1}+\gamma R_{j}-(\beta+t) n^{1}-(\beta+\alpha t) n_{j}^{0}-p_{j} \\
& u_{j}^{0}=y_{j}^{0}-(\beta+\alpha t)\left(n_{j}^{0}+n^{1}\right)-\alpha p_{j}
\end{aligned}
$$

According to [10] and [11], growth controls raise land rents everywhere in the city, inducing a part of the renter population to move to another city. The size of the controlling city declines, whereas the size of the other cities increases. As regards the renter population of the controlling city, the growth control thus affects their utility level in two different ways. On the one hand, the population decline raises the quality of life, which in turn increases their level of utility. On the other hand, the renters' utility level is reduced by the increase in land rent caused by the growth control. In the remaining cities (that do not have set growth controls), the utility level has to decline because the in-migration from the city that set the 
growth control reduces the quality of life. In the resulting inter-urban equilibrium with growth controls, the renters' prevailing utility level will therefore be lower than without growth controls. To reach this equilibrium, the negative utility effect in the active city has to dominate the positive effect. The homeowners' utility level, on the contrary, generally rises when a growth control is introduced, due to the combined effect of a higher quality of life and the control-induced rent increases.

\subsection{Inter-urban equilibrium}

The decision to move. As explained above, only renters are mobile between cities. They move when they observe that they can attain a higher utility level in another city. The literature generally assumes that individuals are perfectly aware of any difference between utility levels of any two cities. Under this view, an inter-urban equilibrium is attained when city populations have adjusted so as to perfectly equalize utility levels everywhere. Contrary to this assumption, we suppose that individuals have an imperfect perception of the utility levels attainable in other cities. More precisely, we assume that they are unable to observe policy choices and income levels in all other cities of the urban system, whereas actual city sizes are considered as known. ${ }^{4}$ The level of knowledge of a renter living in city $i$ concerning earnings and policy choices in city $j$ is designated by the term $w_{i j}$. He is perfectly aware of what happens in his own city $\left(w_{i i}=1\right)$, but his perception is imperfect for all other cities $\left(w_{i j}<1\right.$ for $\left.i \neq j\right)$.

This creates a gap between the utility actually realized in city $j$, given by equation [13], and the perception of city $j$ 's utility level by the inhabitants of city $i$ :

$$
\tilde{u}_{i j}^{0}=w_{i j}\left(y_{j}^{0}-\alpha p_{j}\right)-(\beta+\alpha t) n_{j}
$$

\footnotetext{
${ }^{4}$ This assumption is necessary in order to obtain a closed form solution, but we are convinced that it has some realistic foundations. Compared to local policy choices and living conditions, the general size distribution of cities seems to be well-known and, otherwise, easily verifiable.
} 
A renter moves to another city when the utility level in his place of residence is lower than his perception of the utility he could realize elsewhere. The less reliable a city $i$ resident's information on city $j$ 's income level and policy choice is, the more he will base his judgment of the utility level in city $j$ on the city's actual size, which is the only information he captures with no noise. In consequence, he will more easily move to cities he knows better, whereas changes in cities he knows less have to be considerable before he will consider relocating.

As in models of yardstick competition (Salmon 1987; Besley and Case 1995), individuals judge their own local government on the basis of a comparison with the local governments of other jurisdictions. However, contrary to the yardstick competition case, this comparison of political choices in their hometown and in other cities does not condition the electoral choices of individuals, but their mobility choices. Our model is therefore not actually one of yardstick competition but is better adapted to the category of what Brueckner (2003) refers to as "resource flow models".

Inter-urban equilibrium. An inter-urban equilibrium is attained when no renter perceives any utility differences between his place of residence and the other cities anymore:

$$
y_{i}^{0}-\alpha p_{i}-(\beta+\alpha t)\left(n^{1}+n_{i}^{0}\right)=w_{i j}\left(y_{j}^{0}-\alpha p_{j}\right)-(\beta+\alpha t)\left(n^{1}+n_{j}^{0}\right) \forall i, j
$$

Summed up over all cities $j$, equation [15] can be expressed as:

$$
(J+1)\left(y_{i}^{0}-\alpha p_{i}-(\beta+\alpha t) n_{i}^{0}\right)=\sum_{j=0}^{J} w_{i j} y_{j}^{0}-\alpha \sum_{j=0}^{J} w_{i j} p_{j}-(\beta+\alpha t) N^{0}
$$

With $w_{i i}=1$ and under the assumption that city 0 is passive $\left(p_{0}=0\right)^{5}$, this simplifies to:

$$
n_{i}^{0}\left(p_{i}, p_{j}\right)=\frac{1}{(J+1)(\beta+\alpha t)}\left(J y_{i}^{0}-\sum_{\substack{j=0 \\ j \neq i}}^{J} w_{i j} y_{j}^{0}-\alpha J p_{i}+\alpha \sum_{\substack{j=1 \\ j \neq i}}^{J} w_{i j} p_{j}+(\beta+\alpha t) N^{0}\right) \forall i, j
$$

\footnotetext{
${ }^{5}$ The city 0 has to be passive since we examine a closed system of cities and assume that land consumption is fixed.
} 
Equation [17] indicates the population sizes that guarantee an inter-urban equilibrium contingent on the characteristics and the growth control choices made by all cities in the urban system.

If the local government in city $i$ decides to set stricter growth controls by increasing the development fee $p_{i}$, land rents will rise, lowering the utility level in $i$. As concerns the renters, this clearly decreases their utility level and, consequently, a part of them will decide to move to another city. As a result, the population size of city $i$ will decline. On the contrary, an increase in the degree of severity of growth controls in another city $j$ will have the inverse effect on population size in $i$, the magnitude of the effect depending on the parameters $\beta$ and $t$, and the population's level of knowledge of political choices in $j$.

An increase in the income of the residents of city $i$ raises the local utility level, making the city more attractive than the other cities in the urban system. According to equation [17], this will cause in-migration to city $i$ and increase the city's population until a new inter-urban equilibrium is reached, in which the general utility level is higher than before. Thus, under mobility, an income increase in one single city makes households in the whole urban system better off. If income rises in any other city, city $i$ becomes less attractive in comparison, encouraging a part of its population to leave. The magnitude of the population decline in city $i$ depends on the magnitude of parameters $\beta$ and $t$, and on the extent to which the residents of $i$ become aware of the higher income realized elsewhere.

\subsection{Local public decision-making in the presence of interdependencies}

We assume that local politicians are opportunistic and that they seek to maximize their own personal interests. We distinguish two cases: a first one in which the mayor's only interest is to maximize his share of votes at the next elections, and a second one in which the mayor is not only interested in winning elections but also receptive to the promises made by 
local lobbying groups. This distinction has important implications with respect to the private interests taken into account by the mayor's growth control decision. In the first case, only the interests of the local (i.e., voting) population, that is, of resident homeowners and renters, are taken into consideration. In the second case, the mayor's decision takes a much larger spectrum of interests into account, including, in addition to the local population, the owners of developed and undeveloped land whether they live in the city or not.

Voting. Let us first suppose that the mayor's only interest is to maximize his share of votes at the next elections. According to [12] and [13], a city's population can be divided into two distinct groups of voters, renters $(k=0)$ and resident homeowners $(k=1)$, with divergent preferences for growth controls. The probability that an individual will vote for the mayor in office depends on two factors: (1) the utility level he will reach under the mayor's policy choice (compared to his utility under the opposition's policy choice), and (2) his personal esteem for the mayor. This individual bias in favor of the mayor or his opponent is a random factor, which is uniformly distributed over the real interval $\left[-\omega^{k} / 2 ; \omega^{k} / 2\right]$. Its density $\omega^{k}$ reflects the sensitivity of the voters in group $k$ to policy changes.

Under these standard assumptions of probabilistic voting, maximizing expected plurality is equivalent to the maximization of a social welfare function in which the utility of each group is weighted by its relative size and its sensitivity to policy changes (see, for example, Coughlin et al. 1990). If we assume that $\omega^{0}=\omega^{1}$ for the purpose of simplification, the mayor's objective function can then be written as:

$$
\pi_{i}^{V}=\left(1-\theta_{i}\right) u_{i}^{0}+\theta_{i} u_{i}^{1}
$$

where $\theta$ and $(1-\theta)$ are the shares of homeowners and renters in the local population.

The renter population is unambiguously opposed to growth controls. As mentioned above, the adoption of an entry fee $p_{i}$ improves the local quality of life but, at the same time, 
it tends to increase land rents, and in order to reach a new inter-urban equilibrium, this negative utility effect has to prevail over the positive effect.

The homeowners, on the contrary, approve growth controls, since the increased land rents induced by the controls raise their rental income $\gamma R_{i}$. More precisely, the total land rent that is realized in a given city is equal to the sum of land rents paid by all homeowners and all renters:

$$
\begin{aligned}
R_{i} & =\int_{0}^{\hat{x}_{i}} r_{i}^{0}(x) d x+\int_{\hat{x}_{i}}^{\bar{x}_{i}} r_{i}^{1}(x) d x \\
& =\frac{t}{2}\left(\alpha\left(n_{i}^{0}\right)^{2}+\left(n^{1}\right)^{2}\right)+t \alpha n_{i}^{0} n^{1}+p_{i}\left(\alpha n_{i}^{0}+n^{1}\right)
\end{aligned}
$$

Aggregate land rents increase with rising entry fees insofar as the gains due to higher rents at the interior of the city outweigh the loss of rents at the fringe due to declining city size.

The mayors of all active cities simultaneously and non-cooperatively choose the boundary rents $p_{i}$ that maximize their respective objective functions $\pi_{i}^{V}$. In a Nash equilibrium, their choices of development fees are mutual best responses. Substituting [17] and [19] in [18], we obtain the objective function of the government of city $i$ as a function of its own fee $p_{i}$ and of the fees chosen by the other active governments. Maximization of this objective function with respect to $p_{i}$ determines city $i$ 's optimal growth control choice depending on the growth control choices made by the other cities:

$$
p_{i}{ }^{V}=a_{0}{ }^{V}-a_{1}{ }^{V} \frac{\left(1-\theta_{i}\right)}{\theta_{i}}+a_{2} y_{i}^{0}-a_{3} \sum_{\substack{j=0 \\ j \neq i}}^{J} w_{i j} y_{j}^{0}+a_{4} \sum_{\substack{j=1 \\ j \neq i}}^{J} w_{i j} p_{j}
$$

with: $a_{0}{ }^{V}=\left((J+1) A_{0}(\alpha J-(J+1)) / \gamma+\left(\alpha N^{0}+N^{1}\right)(J+1) A_{0}-\left(N^{0}+N^{1}\right) \alpha^{2} t J\right) A_{0} / \alpha A_{1} ;$

$a_{1}{ }^{V}=(J+1) A_{0}{ }^{2} / \gamma A_{1} \geq 0 ; a_{2}=J((J+1) \beta+\alpha t) / A_{1} \geq 0 ; a_{3}=a_{2} / J \geq 0 ; a_{4}=\alpha a_{3} \geq 0 ;$

$A_{0}=\alpha t+\beta ; A_{1}=\alpha J\left(2(J+1) A_{0}-\alpha t J\right)$. The sufficient condition for a maximum is always met, as can be easily verified. 
According to equation [20], a higher homeownership rate or a higher income level in city $i$ will ceteris paribus be associated with a stricter growth control policy, whereas rising income levels in other cities will induce the mayor of $i$ to reduce his effort to control growth. The best response of city $i$ to a change in the growth control politics of any other city $j$ is given by the partial derivative of [20] with respect to $p_{j}$ :

$$
\frac{\partial p_{i}}{\partial p_{j}}=a_{4} w_{i j} \geq 0
$$

Equation [21] indicates that the growth control choices of two cities are strategic complements: if city $j$ enacts more stringent controls, this will encourage a part of its population to move to another city. The growth controls implemented in $j$ increase the growth pressure in the rest of the urban system and, in response to this, other cities will be tempted to set stricter controls as well. The intensity of city $i$ 's response to a policy change in $j$ depends on $w_{i j}$, that is, the extent to which city $i$ residents are aware of changes in $j$. Only if households living in city $i$ take notice of a policy change in $j$ will they consider migrating, and only in this case will the local government in $i$ react to a policy change in $j$. Voting and lobbying. Let us now suppose that local politicians are not only interested in maximizing votes but that they are also influenced by the contributions offered by local landrelated lobbying groups, i.e., that their objective function includes both the general welfare of the electorate and the contributions $C$ received from organized interest groups as arguments. Aggregate contributions can be written as $C_{i}=\sum_{m} \phi_{i}^{m} c_{i}^{m}$, where $c_{i}^{m}$ is the contribution of a single representative member of interest group $m$, and $\phi_{i}^{m}$ represents the size of interest group $m$, i.e., the number of members. Each group offers a menu of contributions, contingent on the mayor's policy choice, i.e., $c_{i}^{m}=c_{i}^{m}\left(p_{i}\right)$. As Bernheim and Whinston (1986) have shown, the optimal contribution for each interest group $m$ is equal to its objective function 
$I_{i}^{m}\left(p_{i}\right)$ minus a constant $K^{m}: c_{i}^{m}\left(p_{i}\right)=I_{i}^{m}\left(p_{i}\right)-K^{m}$. Under these hypotheses, the local government's objective function can then be written as the weighted sum of the voters' welfare and the lobbying groups' interests.

In the case of growth controls, the major lobbying groups concerned are the owners of developed and undeveloped land. As explained in the introduction, the owners of developed land can either be resident homeowners or absentee landlords. In what follows, we assume that only the latter engage in lobbying activities. As regards the landlords, their primary interest lies in maximizing aggregated land rent, given by equation [19]. They thus encourage stricter controls insofar as aggregate land rent continues to rise.

The owners of undeveloped land, on the contrary, are strictly opposed to growth controls. Since growth controls limit city size, they prevent landowners next to the city limit from developing their land and from realizing a positive land rent. The owners of land that remains undeveloped due to the adoption of growth controls are thus strictly opposed to such policies. We suppose that these owners of undeveloped land still have a stake in the city's decision-making process, even if they are formally no longer part of the city, and for the sake of simplicity, we further assume that their benefits are proportional to city size $\bar{x}_{i}$.

In summary, the mayor's objective function can thus be expressed as:

$$
\pi_{i}^{V L}=\left(1-\theta_{i}\right) u_{i}^{0}+\theta_{i} u_{i}^{1}+\phi_{i}^{D} R_{i}+\phi_{i}^{U} \bar{x}_{i}
$$

As before, we assume that all mayors simultaneously and independently choose the boundary rents $p_{i}$ that maximize their objective function. Under this hypothesis, the best response function of the mayor of city $i$ can be represented as follows:

$$
p_{i}^{V L^{\prime}}=a_{0}^{V L^{\prime}}-\frac{\left(a_{11}{ }^{V L^{\prime}} \theta_{i}+a_{12}{ }^{V L^{\prime}} \phi_{i}^{U}+a_{13}{ }^{V L^{\prime}}\right)}{\left(\theta_{i} \gamma+\phi_{i}^{D}\right)}+a_{2} y_{i}^{0}-a_{3} \sum_{\substack{j=0 \\ j \neq i}}^{J} w_{i j} y_{j}^{0}+a_{4} \sum_{\substack{j=1 \\ j \neq i}}^{J} w_{i j} p_{j}
$$


with: $a_{0}{ }^{V L^{\prime}}=A_{0}\left(\left((J+1) A_{0}-\alpha^{2} t J\right) N^{1}+\alpha((J+1) \beta+\alpha t) N^{0}\right) / \alpha A_{1} \geq 0$

$a_{11}^{V L^{\prime}}=(1-\alpha)(J+1)^{2} A_{0}{ }^{2} / \alpha A_{1} ; a_{12}^{V L^{\prime}}=\alpha J(J+1) A_{0} / A_{1} ; a_{13}{ }^{V L^{\prime}}=(J+1) A_{0}{ }^{2} / A_{1}$.

In contrast to the first case where the share of homeowners had a clearly positive direct effect on the stringency of the mayor's growth control choice, the variable's influence is now indeterminate.

Equation [23] can be further simplified. According to Hilber and Robert-Nicoud (2007), it can be argued that the influence of the owners of developed land acting as landlords should be proportional to the share in local housing that they represent or, put differently, to the share of renters in the local population. If this is the case, and if one makes the additional hypothesis that the share of land rents that a landlord perceives is comparable to that of a resident homeowner, i.e., $\gamma$, the denominator $\theta_{i} \gamma+\phi_{i}^{D}$ simply becomes a constant, $C$. In this case, the best response function of city $i$ simplifies to:

$$
p_{i}^{V L}=a_{0}^{V L}-a_{11}^{V L} \theta_{i}-a_{12}{ }^{V L} \phi_{i}^{U}+a_{2} y_{i}^{0}-a_{3} \sum_{\substack{j=0 \\ j \neq i}}^{J} w_{i j} y_{j}^{0}+a_{4} \sum_{\substack{j=1 \\ j \neq i}}^{J} w_{i j} p_{j}
$$

with: $a_{0}{ }^{V L}=A_{0}\left(\left((J+1) A_{0}-\alpha^{2} t J\right) N^{1}+\alpha((J+1) \beta+\alpha t) N^{0}-(J+1) \alpha A_{0}\right) / \alpha A_{1}$; $a_{11}{ }^{V L}=a_{11}{ }^{V L^{\prime}} / C \geq 0 ; a_{12}{ }^{V L}=a_{12}{ }^{V L^{\prime}} / C \geq 0$. As before, the sufficient condition for a maximum is always met. The parameters $a_{2}$ to $a_{4}$ are identical to the first case. A mayor's reaction to policy changes or changes in the income level in a neighboring city is thus the same as before. Notably, growth control choices of neighboring cities are strategic complements as before.

The most important change concerns the relationship between the share of homeowners in the local population and the stringency of controls, which is now clearly negative. This result can be explained quite simply. Due to their double identity as inhabitants and owners of developed land, the resident homeowners' preferred policy choice is stricter than the preferred choice of the renter population, but less strict than the "absentee" 
homeowners' preferred policy, as has been shown by Brueckner and Lai (1996). If we assume, like Hilber and Robert-Nicoud (2007), that the influence of the absentee homeowners acting as landlords is proportional to their share in local housing, it can then be argued that an increase in the percentage of homeowners in the local population does not only diminish the impact of the renters' opposition to the instauration of growth controls, but the influence of the landlords in favor of such policies as well. If this second effect prevails over the first, it might thus be possible to observe a negative relationship between the share of homeowners in the local population and the stringency of the growth controls enacted. In this case, it is possible that the growth control choice will be less stringent, the greater the share of homeowners - notwithstanding the fact that resident homeowners are by no means opposed to growth controls.

In matrix form, equations [20] and [24] describing the interactions between local growth control decisions within the urban system (depending on the hypothesis regarding the influence of voters and lobbying groups) can be expressed as:

$$
\begin{aligned}
& \mathbf{p}^{V}=a_{0}^{V} \mathbf{t}-a_{1}^{V} \mathbf{t}+a_{2} \mathbf{y}-a_{3} \mathbf{W} \mathbf{y}+a_{4} \mathbf{W} \mathbf{p} \\
& \mathbf{p}^{V L}=a_{0}^{V L} \mathbf{} \mathbf{t}-a_{11}^{V L} \mathbf{\theta}-a_{12}^{V L} \mathbf{\varphi}^{\mathbf{U}}+a_{2} \mathbf{y}-a_{3} \mathbf{W} \mathbf{y}+a_{4} \mathbf{W} \mathbf{p}
\end{aligned}
$$

where $\mathbf{p}$ is the $J \times 1$ vector of the cities' growth control choices, $\mathbf{t}$ is a $J \times 1$ vector of the relative influence of homeowner and renter voters with representative element $t_{i}=\left(1-\theta_{i}\right) / \theta_{i}$, $\boldsymbol{\theta}$ and $\varphi$ are $J \times 1$ vectors representing the homeownership rate and the lobbying efforts of landowners, $\mathbf{y}$ is the $J \times 1$ vector of household income, $\mathbf{\imath}$ is a $J \times 1$ vector of ones and $\mathbf{w}$ the $J \times J$ matrix of the terms $w_{i j}$, representing the population's level of knowledge of what happens in other cities. 


\section{Empirical framework}

In our theoretical framework, we emphasize that a city's population cannot be perfectly informed about political choices and living conditions in all other cities, and we show how this limited perception conditions its location choices and thereby the intensity of strategic interactions between cities regarding growth control decisions.

It seems quite natural to us to assume that the residents of a city more easily notice what happens in nearby cities compared to more distant ones, due, for example, to their daily travel habits (work, shopping, etc.) and to information provided by regional newspapers and other local media. If this hypothesis is accepted, strategic interactions between cities will then take on a spatial pattern. Under this hypothesis, the matrix $\mathbf{w}$ can be understood as a spatial weight matrix. Our theoretically-derived equations [25] and [26] can then be interpreted as spatial autoregressive models (Anselin 1988), making spatial econometrics a natural tool for their estimation.

Our empirical study concerns local growth control decisions in the French Rhône Department (one of the 96 French administrative divisions), located in the central eastern part of France. The department is composed of 293 municipalities, the largest being Lyon, one of the mayor cities in France. (Over 75\% of the department's population actually lives in the agglomeration of Lyon.) The present section details our estimation approach and the data used to test the presence of spatial strategic interactions across cities and the impact of private interests on local political decisions regarding growth control choices.

\subsection{Econometric issues}

In order to estimate growth control choices in equilibrium, we have rewritten our theoretically derived reaction functions as follows:

$$
\mathbf{p}=\alpha_{0} \mathbf{l}+\alpha_{11} \boldsymbol{\theta} \mathbf{z}+\alpha_{12} \boldsymbol{\varphi}^{U}+\alpha_{2} \mathbf{y}+\alpha_{3} \mathbf{W} \mathbf{y}+\rho \mathbf{W} \mathbf{p}+\varepsilon
$$


where $\varepsilon$ is a $J \times 1$ vector of normally and identically distributed (nid) error terms, and where the parameters from the theoretical model $a_{k}(k=0,1,2,3)$ have been replaced by $\alpha_{k}$, and $a_{4}$ by $\rho$, as is usual in the spatial econometrics literature. By estimating this single equation, we can discriminate between the two cases (voting and voting \& lobbying) distinguished in the theoretical model. If the first case is valid, $\alpha_{11}$ should be positive and $\alpha_{12}$ equal to zero. If the second case is valid, both $\alpha_{11}$ and $\alpha_{12}$ should be negative. ${ }^{6}$

Equation [27] is a spatial lag specification whose OLS estimation is affected by a simultaneity bias, resulting in biased and inconsistent parameter estimates (Anselin 1988). To overcome this problem, we estimate our model using Maximum Likelihood (ML) estimation. In addition, we perform Bayesian Markov Chain Monte Carlo (MCMC) methods in order to check the robustness of our results to heteroscedasticity and potential outliers, and to take the censoring of our data into account. ${ }^{7}$ The regularity conditions of the maximum likelihood estimators are described in Lee (2004), and the Bayesian heteroscedastic MCMC estimation method is developed in LeSage (1997).

The elements of weight matrix $\mathbf{w}$ are specified so as to reflect our prior expectation that the residents of a city more easily notice what happens in nearby cities compared to more distant ones. To encounter the risk of arbitrariness, we present results for three different specifications of $\mathbf{w}$. Our base specification assumes that the inhabitants of every city observe what happens in the same number of neighboring cities, setting the number of neighbors arbitrarily to five. We thus set $w_{i j}^{*}=1$ for the elements indicating the interactions between city $i$ and its five nearest neighbors, and $w_{i j}^{*}=0$ for all others. In order to check the robustness of

\footnotetext{
${ }^{6}$ It is important to stress that the parameters $\alpha_{k}$ cannot directly be interpreted as the explanatory variables' marginal impacts. In a spatial model, a change in an explanatory variable for a single city can potentially affect the dependent variables in all other cities, and this will cause feedback effects on the first. Therefore, when evaluating the marginal impacts, these feedback loops have to be taken into account (see Ertur and Koch 2007 or LeSage and Pace 2009 for a discussion of this issue).

${ }^{7}$ The underlying functions are kindly provided by James LeSage in his Spatial Econometrics Toolbox for Matlab (http://www.spatial-econometrics.com).
} 
our results, we also perform estimations using two other matrices with varying weights based on the distance between cities. The first one states that the accuracy of a household's perception of another city's living conditions and political choices diminishes directly with the distance between the two cities. Every element $w_{i j}{ }^{*}$ of the un-standardized matrix $\mathbf{W}^{*}$ is equal to $w_{i j}^{*}=1 / d_{i j}$, where $d_{i j}$ represents the great-circle distance between the cities $i$ and $j$. Finally, in the third case we use the inverse of squared distance, $w_{i j}^{*}=1 / d_{i j}^{2}$, which means that the household's perception of what happens in other cities is even more sensitive to distance than in the second case.

The weight matrices are row-standardized so that the sum of every line is equal to 1 . Therefore, the elements of the standardized matrix are: $w_{i j}=w_{i j}^{*} / \sum_{j} w_{i j}^{*}$. With this standardization, the term $\sum_{j} w_{i j} p_{j}$ simply represents the weighted average of the other cities' political choices as observed by the residents of city $i$. By convention, $w_{i i}$ is set to zero $\forall i .^{8}$

\subsection{The growth control variable}

Our empirical study concerns the TLE (“taxe locale d'équipement"), a French local development tax similar to North American impact fees, which has to be paid by the developer when he is granted a building permit by the municipality. The TLE aims at making developers contribute to the costs of public equipment and infrastructures. However, unlike impact fees in the United States, the revenues generated by the TLE are not bound to the financing of amenities for the new developments (i.e., there are no "rational nexus"

\footnotetext{
${ }^{8}$ Note that contrary to this, in the theoretical part, we have assumed that individuals perfectly observe what happens in their own city, which means $w_{i i}=1$. However, the theoretically derived equations for cities' growth control choices excluded the city's own policy choice in the term representing the weighted growth control choices of the other cities. This is the same as including the case $i=j$, but giving it the weight zero. Thus, our theoretical model and the empirical framework are compatible.
} 
conditions). ${ }^{9}$ The amount to be paid by the beneficiary of the building permit is based on an administratively assessed value of the building. This is determined on a lump-sum basis as the product of the net built surface and a constant value per square meter, which depends on the type of building (agricultural, industrial, residential, etc.) and currently varies between $€ 95$ and $€ 640$ (€98-704 in the greater Paris region). The so determined estimated value of the building is multiplied by the rate of the TLE decided by the municipality (which can also vary between building types). This rate can be raised up to $5 \%$ by the city council. It is the political choice regarding this rate that our analysis is interested in. More precisely, we analyze the mean rates applied by each of the 293 municipalities in the Rhône Department. Our data concerns the year 2007 and comes from the French ministry in charge of land use and town planning.

\subsection{Explanatory variables}

Our empirical study seeks to evaluate the influence of the different private interests that might be affected by the mayor's decision to restrict local growth, whether expressed via voting or lobbying. In doing so, it indirectly makes it possible to discriminate between the two cases described in our theoretical model, i.e., to establish if the political choice regarding the TLE rate is primarily determined by the mayor's desire to get re-elected or if he is also receptive to the promises made by lobbying groups. If our estimations reveal a positive link between the homeownership rate and the stringency of the TLE rate chosen and if none of the non-voter lobbying groups exert a significant influence on the decisions made, this would be a clear sign in favor of the first case; otherwise, the second case would have to be favored.

\footnotetext{
${ }^{9}$ Besides that, the TLE does not necessarily apply to large urban development zones ("zones d'aménagement concerté"), where the sharing of infrastructure and other public amenity costs can be directly negotiated between the municipality and the developer. Unfortunately, data concerning these negotiated contribution schemes are not easily available.
} 
As we do not have any direct measures of the pressures exerted by the different groups, we approximate their influence by their simple presence, i.e., the groups' local numerical importance. The relative influence of resident homeowners and renters is represented by the homeownership rate in the local population, and the pressure exerted by the owners of undeveloped land is approximated by the percentage of farmers in the local active population. These are census data provided by the French National Statistical Institute (INSEE) and refer to the year 2006. The lobbying of the owners of developed land acting as landlords is approximated by the percentage of local employees working in the field of real estate activities. In fact, we suppose that a large percentage of the landlords confer the administration of their property to a realtor, and since the remuneration of these realtors is generally calculated as a percentage of the rent the property procures to its owner, the realtors pursue the same interest as the owners, i.e., the maximization of this rent.

In accordance with Lubell et al. (2005) and Glaeser and Ward (2009), we assume that the pressure exerted by the "growth machines" lobby may be taken into account by the economic activity in the construction sector. Accordingly, we use the percentage of local employees working in the construction sector. The data for both variables (the landlords' and the growth machines' lobbies) comes from the French Unemployment Insurance Agency (Unédic) and refers to the year 2006..$^{10}$

Moreover, a city's choice regarding the TLE-rate depends on the income level of its population, on the population's knowledge of income and on policy choices in other cities. Income is measured as the median of taxable income per household in 2006, published by INSEE-DGI. ${ }^{11}$ Summary statistics for all variables are presented in Table 1.

\footnotetext{
10 Employment as measured by Unédic includes all employees of industrial or commercial private sector establishments that employ at least one person under a labor contract. For municipalities that belong to an association of municipalities ("établissement public de cooperation intercommunale"), the two variables are calculated on the level of this association.

${ }^{11}$ INSEE is the French National Statistical Institute and DGI is similar to the US Internal Revenue Service.
} 
The theoretical model developed above highlights the importance of the political determinants of growth controls, but this does not eliminate the possibility that other factors may play a role as well. Empirical studies on the non-political determinants of growth controls in North American cities have stressed the impact of prior population growth and population density (Bates and Santerre 1994; Evenson and Wheaton 2003; Glaeser and Ward 2009). In addition, it seems that the fiscal stress in indebted municipalities mitigates political growth management decisions (Diaz and Green 2001). In our robustness analysis, we therefore introduce three supplementary explanatory variables: population density, the rate of population growth between 1999 and 2006, and public debt per capita. These three variables should all be positively correlated with the average rate of the TLE. In more densely populated municipalities, the negative externalities related to growth should be felt more intensely by the local population, and in highly indebted municipalities, the pressure to make new residents contribute to the financing of new infrastructures should likewise be stronger. In municipalities that experienced strong prior population growth, we expect that both the desire to limit negative externalities and to fairly distribute infrastructure costs will be stronger.

Population density is measured as the number of inhabitants per square kilometer. It is based on population data from the 2006 census and on data on the surface area of the municipalities provided by the French National Geographic Institute (IGN). The data concerning public debt per capita in 2006 comes from the French Ministry of the Interior.

\section{$4 \quad$ Empirical results}

Contrary to other empirical studies of local strategic interactions using spatial econometrics (see Brueckner 2003 for a review), our empirical model is formally derived 
from the theoretical modeling of growth control decision-making. Our benchmark estimation is based on equation [27], which constitutes a spatial autoregressive model.

In our benchmark case, the empirical model is estimated by Maximum Likelihood using the five-nearest-neighbors weight matrix. However, the assumption of spatial interactions needs to be tested, that is we have to control not only whether the spatial parameter $\rho$ is significantly different from 0 , but to test the null hypothesis of absence of spatial interdependencies. ${ }^{12}$ In order to discriminate between the two forms of spatial dependence (spatial error and spatial lag) and to test if our theoretically derived functional form is effectively the most appropriate empirical specification, we initially estimate the model by OLS and perform the robust Lagrange Multiplier tests, which have good power against their specific alternative (Anselin et al. 1996).

The results of these tests are presented in Table 2. Above all, they show that the robust test statistic for an omitted spatial lag of the endogenous variable is more significant than that for omitted spatial error correlation. Following the specification search rule proposed by Anselin and Florax (1995) and Florax et al. (2003), this leads us to the conclusion that the spatial autoregressive specification [27] deduced from our theoretical model seems to be more appropriate than a spatial error model would be.

\subsection{Benchmark results}

The results of Maximum Likelihood Estimation of the spatial autoregressive model, using the five-nearest-neighbors weight matrix, are summarized in the first column of Table 3. They globally confirm our theoretical model. The estimate of the spatial autocorrelation parameter $\rho$ is significantly different from zero, indicating that cities engage in strategic

\footnotetext{
${ }^{12}$ We perform the usual spatial tests (i.e., the Moran's I test of Cliff and Ord 1981 and the Lagrange Multiplier tests LMERR and LMLAG developed by Burridge 1980 and Anselin 1988), using the basic five-nearest neighbors-weight matrix.
} 
interaction with neighboring cities. Since $\rho$ is positive, cities' growth control choices are indeed strategic complements, as predicted by equations [20] and [24].

As expected, the parameter estimate associated with a city's own income is positive and significant. This result is consistent with the findings of Pogodzinski and Sass (1994), Evenson and Wheaton (2003) and McDonald and McMillen (2004), showing that controls are more stringent in municipalities with higher income levels. The estimate of income in neighboring municipalities, on the contrary, is not significantly different from zero.

Our results also globally confirm the hypothesis that local growth control choices are influenced by diverse land-based interest groups. First of all, it can be observed that the coefficient associated with the relative influence of resident homeowners and renters is not only significant but has a negative sign. This is contrary to the prediction of the voting case of our model but coherent with the second case that combines voting and lobbying. Recalling that no consensus emerges from the existing literature regarding the pressure exerted by resident homeowners, this result is in accordance with the findings of Clingermayer (1993), Pogodzinski and Sass (1994) and Glaeser and Ward (2009), but contradicts the positive influence detected by Dubin et al. (1992). Thus, our result seems to indicate that the mayors in the Rhône Department are not only responsive to the interests of their constituency, but to the pressure exerted by special interest lobbying groups as well. This interpretation is further confirmed by the fact that the coefficient of the real estate variable is positive, as expected, and significant, suggesting successful lobbying of landlords for stricter growth controls. Furthermore, our findings support the hypothesis that the owners of undeveloped land exert sizable influence on local decisions regarding impact fees since the associated parameter estimate is different from zero at the $99 \%$ significance level and negative, as expected. On the contrary, the lobbying activities of the construction sector do not seem to influence local choices of TLE rates. 


\subsection{Robustness analysis}

We further check the robustness of our benchmark results in several directions, testing for the presence of additional spatial autocorrelation in the residuals, as well as the consistency of estimates to alternative spatial patterns and to additional explanatory variables, and to potential heteroscedasticity and outlier problems. In addition, we take the censoring of the data into account (due to the fact that municipalities only can choose TLE rates up to 5\%) by estimating a Bayesian spatial Tobit model.

First of all, we estimated a general spatial model (GSM) that, in addition to the spatial lags of the endogenous TLE and the exogenous income variables, allows for spatial dependence in the disturbances, i.e.:

$$
\boldsymbol{\varepsilon}=\lambda \mathbf{W} \boldsymbol{\varepsilon}+\mathbf{u}
$$

where $\mathbf{u}$ is a vector of nid error terms. The results are reported in the second column of Table 3. Compared to our benchmark SAR specification, the GSM model's predictive power is barely better, and the additional spatial parameter $\lambda$ is not significantly different from zero. More importantly, allowing for a spatial autoregressive error term does not undermine the role played by spatial strategic interactions. The spatial parameter $\rho$ is still significant and its estimated value only slightly changes. All other results remain stable as well.

Secondly, we extend the benchmark model to additional variables that are supposed to account for alternative determinants of growth control decisions. In doing so, we also verify that the estimated parameter representing the spatial strategic interaction is not artificially increased because of omitted spatially correlated variables. As specified above, we introduce three supplementary variables: population density, the prior rate of population growth, and the municipality's public debt per capita. According to the value of the log-likelihood functions and the Akaike and Schwarz information criteria, the inclusion of these variables improves the explanatory strength of the estimations. 
According to our results, which are presented in the third column of Table 3, public debt and prior growth rates do not seem to be associated with local choices regarding TLE rates. The parameter estimate associated with population density, on the contrary, has the expected positive sign and is significantly different from zero at the $99 \%$ significance level. Consistent with the findings of Evenson and Wheaton (2003), this result lends a certain credibility to the hypothesis that local growth controls are at least partly set up in order to limit negative externalities.

Most of the other results remain unchanged, besides the fact that the income in neighboring municipalities now becomes significant. In contrast to the predictions of our theoretical model, the estimate has a positive sign. This result can probably be explained by the fact that the variable $y$ in our theoretical model is associated with cities and not with households. It therefore probably better describes the economic attractiveness of a city than a household's ability to attain a certain revenue level. Unfortunately, we do not have any variable at hand that could describe this economic attractiveness.

Nevertheless, the results still indicate significant and positive spatial interactions between jurisdictions. As regards the influence of the owners of developed and undeveloped land, the results confirm the influence exerted by the owners of undeveloped land who successfully lobby for less stringent impact fees. The influence of the owners of developed land, on the contrary, is weaker than in our benchmark model. The variable associated with the lobbying of real estate professionals and landlords is still positive and significantly different from zero, but the homeownership rate, representing the relative influence of local voters, divided into homeowners and renters, fails to gain significance. This last result further corroborates the hypothesis that local political decisions regarding growth controls seem to be influenced by the lobbying of organized special interests rather than by the local populations' concerns. 
In a third series of robustness checks, we applied Bayesian Markov Chain Monte Carlo (MCMC) methods in order to take the censoring of the TLE rates into account, which are in fact limited to values up to $5 \%$. More precisely, we estimate a SAR Tobit model using the approach suggested by LeSage and Pace (2009). Unobserved latent TLE choices are assumed to follow a truncated multivariate normal distribution and sampled using the Gibbs sampler. As suggested by Albert and Chib (1993) and Geweke (1993), we use variance scalars in order to take potential heteroscedasticity and/or outliers into account. ${ }^{13}$ Moreover, we use a uniform prior $U[-1,1]$ for the spatial autocorrelation parameter $\rho$, as suggested by LeSage (1997), and diffuse priors for the other model parameters. We make 10,000 draws of which we discard 1,000 for burn-in. ${ }^{14}$

The results of this Bayesian approach are reported in the last column of Table 3. Local TLE choices are still subject to spatial strategic interactions between municipalities and influenced by the municipality's as well as its neighbors' income levels. As in the preceding estimation, the two variables representing the respective influence of the owners of undeveloped land and of the "absentee" homeowners acting as landlords are both significant and have the expected signs, confirming our hypothesis that these lobbying groups successfully influence local growth control choices.

As before, the estimates of population density are significant and positive, and in contrast to our previous results, the parameter associated with prior population growth is now positive and significant as well. These results thus give further credit to the hypothesis that growth controls are at least partly set up in order to limit the negative externalities related to growth.

In a final series of estimations, we question the way spatial strategic interactions have been modeled and we extend the results to two alternative spatial patterns. We repeat the

\footnotetext{
${ }^{13}$ The value of the hyperparameter $r$ is set to 4 .

${ }^{14}$ Estimations based on 1,000 draws with the first 100 draws omitted yielded results very close to the ones reported below.
} 
Maximum Likelihood Estimation of the extended model as well as the estimation of the SAR Tobit model using two alternative weight matrices: the inverse distance and the squared inverse distance between municipalities. In contrast to a pattern of interactions spatially bound to a set of given neighboring cities as in the case of the five-nearest neighbors weight matrix, these alternatives assume that all cities in the system belong to the set of neighbors, but the influence on neighbors' political choices is now assumed to decrease with distance or even more rapidly with squared distance. Results are reported in Table 4. With little exception, the results remain qualitatively the same. All coefficients take on the same sign as before and remain significant, with the exception of the variable representing the pressure exerted by the absentee homeowners acting as landlords, which is no longer significant when using the inverse distance weight matrix.

\section{Conclusion}

In this paper, we model a municipality's decision to control growth as the result of a political struggle between different groups of voters and lobbies, distinguishing two cases: a first case in which local political decision makers tailor their decisions to their voters' interests in order to get re-elected, and a second one in which, besides seeking re-election, they are also receptive to the promises made by organized lobbying groups. These two cases are fundamentally different with regard to the private interests taken into account by the mayor. In the first case, only homeowners and renters living (and voting) in the municipality can influence the mayor's political choices. In the second case, on the contrary, other interest groups such as local business interests organized into a "growth machine" or "absentee" homeowners acting as landlords can intervene and influence the mayor's decision. Moreover, when the influence of private interests is limited to the local voting population, the greater the percentage of homeowners in the local population is compared to that of renters, the higher 
the TLE rate chosen by the mayor will be. In the second case, however, the link between the homeownership rate and the stringency of the policy adopted by the mayor can be either positive or negative.

Furthermore, assuming that a municipality's decision to control its development raises housing demand in neighboring municipalities, we consider local growth control choices as being spatially interdependent. The inter-city equilibrium resulting from our theoretical model formally takes the form of a spatial autoregressive specification.

Our empirical study focusing on the determinants of municipal choices regarding the TLE in the Rhône Department of France (including the agglomeration of Lyon) confirms most of the predictions of our model. Local choices regarding TLE rates are subject to positive spatial strategic interaction between jurisdictions. This is in line with the results of Brueckner (1998), who also finds evidence that growth control choices of nearby cities are strategic complements. Moreover, our empirical study highlights the important role that lobbying groups appear to play in local growth control decisions, in addition to other motivations for growth controls such as the protection of amenities and the limitation of negative externalities related to growth.

Concerning the influence of the owners of developed land, our results indicate that the real estate agents who are supposed to act on behalf of the homeowners who rent out the apartment they own do indeed successfully lobby for more stringent growth controls. Resident homeowners, however, do not seem to be the driving force for the adoption of growth controls. Accordingly, our results do not support the "homevoter" hypothesis of Fischel (2001), but tend to agree with Brueckner and Lai (1996) and Hilber and RobertNicoud (2007) who highlight the importance of absentee homeowners acting as landlords.

Concerning the role played by the owners of undeveloped land, our results suggest that farmers succeed in preventing stringent growth controls, whereas the construction sector does not seem to play any role in local growth control choices. We therefore find no evidence for 
the existence of urban "growth machines" (Logan and Molotch 1987) in France. Clearly, this question has to be further investigated in order to understand to what extent the "growth machine" phenomenon actually plays a role in today's local politics in France and in European cities, or if it only concerns North American cities.

Acknowledgements We gratefully acknowledge valuable comments from two anonymous referees and helpful suggestions from the Editor-in-Chief of Public Choice. We would like to thank...

Inclure les members du jury? 


\section{References}

Albert, J. H. \& Chib, S. (1993). Bayesian analysis of binary and polychotomous response data. Journal of the American Statistical Association 88(422), 669-679.

Anselin, L. (1988). Spatial econometrics: Methods and models. Dordrecht: Kluwer Academic Publishers.

Anselin, L., Bera, A. K., Florax, R. J. G. M. \& Yoon, M. J. (1996). Simple diagnostic tests for spatial dependence. Regional Science and Urban Economics 26(1), 77-104.

Anselin, L. \& Florax, R. J. G. M. (1995). Small sample properties of tests for spatial dependence in regression models. In Anselin, L. \& Florax, R. J. G. M., New directions in spatial econometrics. Berlin: Springer, 21-74.

Bates, L. J. \& Santerre, R. E. (1994). The determinants of restrictive residential zoning: Some empirical findings. Journal of Regional Science 34(2), 253-263.

Behrens, K. \& Thisse, J.-F. (2007). Regional economics: A new economic geography perspective. Regional Science and Urban Economics 37(4), 457-465.

Bernheim, B. D. \& Whinston, M. D. (1986). Menu auctions, resource allocation, and economic influence. Quarterly Journal of Economics 101(1), 1-31.

Besley, T. \& Case, A. (1995). Incumbent behavior: Vote seeking, tax setting and yardstick competition. American Economic Review 85(1), 25-45.

Brueckner, J. K. (1995). Strategic control of growth in a system of cities. Journal of Public Economics 57(3), 393-416.

Brueckner, J. K. (1998). Testing for strategic interaction among local governments: The case of growth controls. Journal of Urban Economics 44(3), 438-467.

Brueckner, J. K. (1999). Modeling urban growth controls. In Panagariya, A., Portney, P. R. \& Schwab, R. M., Environmental and public economics: Essays in honor of Wallace E. Oates. Cheltenham: Edward Elgar.

Brueckner, J. K. (2003). Strategic interaction among governments: An overview of empirical studies. International Regional Science Review 26(2), 175-188.

Brueckner, J. K. \& Lai, F.-C. (1996). Urban growth controls with resident landowners. Regional Science and Urban Economics 26(2), 125-143.

Burridge, P. (1980). On the Cliff-Ord test for spatial autocorrelation. Journal of the Royal Statistical Society Series B 42(1), 107-108.

Cho, M. \& Linneman, P. (1993). Interjurisdictional spillover effects of land use regulation. Journal of Housing Research 4(1), 131-163.

Cliff, A. D. \& Ord, K. (1981). Spatial processes: Models and applications. London: Pion.

Clingermayer, J. (1993). Distributive politics, ward representation, and the spread of zoning. Public Choice 77(4), 725-738.

Coughlin, P. J., Mueller, D. C. \& Murrell, P. (1990). A model of electoral competition with interest groups. Economics Letters 32(4), 307-311.

Diaz, D. \& Green, G. P. (2001). Fiscal stress and growth management effort in Wisconsin cities, villages, and towns. State and Local Government Review 33(1), 7-22.

Dubin, J. A., Kiewiet, D. R. \& Noussair, C. (1992). Voting on growth control measures: Preferences and strategies. Economics and Politics 4(2), 191-213.

Ertur, C. \& Koch, W. (2007). Growth, technological interdependence and spatial externalities: theory and evidence. Journal of Applied Econometrics 22(6), 1033-1062.

Evenson, B. \& Wheaton, W. C. (2003). Local variations in land use regulations. BrookingsWharton Papers on Urban Affairs 2003(4), 221-260.

Fischel, W. A. (1990). Do growth controls matter? A review of empirical evidence on the effectiveness and efficiency of local government land use regulation. Cambridge, MA: Lincoln Institute of Land Policy. 
Fischel, W. A. (2001). The homevoter hypothesis: How home values influence local government taxation, school finance, and land-use policies. Cambridge: Harvard University Press.

Florax, R. J. G. M., Folmer, H. \& Rey, S. J. (2003). Specification searches in spatial econometrics: The relevance of Hendry's methodology. Regional Science and Urban Economics 33(5), 557-579.

Geweke, J. (1993). Bayesian treatment of the independent Student t linear model. Journal of Applied Econometrics 8(1), 19-40.

Glaeser, E. L., Gyourko, J. \& Saks, R. (2005). Why have housing prices gone up? American Economic Review 95(2), 329-333.

Glaeser, E. L. \& Ward, B. A. (2009). The causes and consequences of land use regulation: Evidence from Greater Boston. Journal of Urban Economics 65(3), 265-278.

Gordon, T. M. (2009). Bargaining in the shadow of the ballot box: causes and consequences of local voter initiatives. Public Choice 141(1-2), 31-48.

Helsley, R. W. \& Strange, W. C. (1995). Strategic growth controls. Regional Science and Urban Economics 25(4), 435-460.

Hilber, C. \& Robert-Nicoud, F. (2007). Homeownership and land use controls: A dynamic model with voting and lobbying. Mimeo, London School of Economics.

Lee, L.-F. (2004). Asymptotic distributions of Quasi-Maximum Likelihood estimators for spatial econometric models. Econometrica 72(6), 1899-1926.

LeSage, J. (1997). Bayesian estimation of Spatial Autoregressive Models. International Regional Science Review 20(1-2), 113-129.

LeSage, J. \& Pace, R. K. (2009). Introduction to spatial econometrics. Boca Raton: Chapman \& Hall/CRC.

Logan, J. R. \& Molotch, H. L. (1987). Urban fortunes: The political economy of place. Berkeley: University of California Press.

Lubell, M., R. Feiock \& E. Ramirez (2005). Political institutions and conservation by local governments. Urban Affairs Review 40(6), 706-729.

McDonald, J. F. \& McMillen, D. P. (2004). Determinants of suburban development controls: A Fischel expedition. Urban Studies 41(2), 341-361.

Molotch, H. L. (1976). The city as a growth machine: Toward a political economy of place. American Journal of Sociology 82(2), 309-332.

Pogodzinski, J. M. \& Sass, T. R. (1994). The theory and estimation of endogenous zoning. Regional Science and Urban Economics 24(5), 601-630.

Pollakowski, H. O. \& Wachter, S. M. (1990). The effects of land-use constraints on housing prices. Land Economics 66(3), 315-324.

Quigley, J. M. \& Rosenthal, L. A. (2005). The effects of land use regulation on the price of housing: What do we know? What can we learn? Cityscape 8(1), 69-137.

Revelli, F. (2005). On spatial public finance empirics. International Tax and Public Finance 12(4), 475-492.

Richer, J. (1995). Explaining the vote for slow growth. Public Choice 82(3-4), 207-223.

Salmon, P. (1987). Decentralisation as an incentive scheme. Oxford Review of Economic Policy 3(2), 24-43. 


\begin{tabular}{|c|c|c|c|c|}
\hline & Mean & Std. dev. & Min & $\operatorname{Max}$ \\
\hline TLE rate & 2.75 & 1.78 & 0.00 & 5.00 \\
\hline $\begin{array}{l}\text { Income per household } \\
\text { (in } € 1,000)\end{array}$ & 31.49 & 7.16 & 16.67 & 56.96 \\
\hline $\begin{array}{l}\% \text { real estate activities } \\
\text { (landlords) }\end{array}$ & 0.83 & 0.62 & 0.11 & 2.15 \\
\hline $\begin{array}{l}\% \text { construction } \\
\text { (growth machines) }\end{array}$ & 12.88 & 6.36 & 1.76 & 28.98 \\
\hline $\begin{array}{l}\text { Homeownership rate } \\
\text { (owner-occupiers) }\end{array}$ & 71.41 & 12.31 & 28.29 & 93.06 \\
\hline $\begin{array}{l}\% \text { farmers } \\
\text { (landowners) }\end{array}$ & 3.59 & 4.62 & 0.00 & 28.57 \\
\hline Supplementary variables & & & & \\
\hline $\begin{array}{l}\text { Population density } \\
\text { (in } 1,000 \text { inhabitants } / \mathrm{km}^{2} \text { ) }\end{array}$ & 4.93 & 10.65 & 0.13 & 98.66 \\
\hline $\begin{array}{l}\text { Public debt } \\
\text { (in } € 1,000 \text { ) }\end{array}$ & 0.51 & 0.45 & 0.00 & 3.56 \\
\hline Population growth 1999-2006 & 9.02 & 8.30 & -12.86 & 41.21 \\
\hline
\end{tabular}

Table 2: Tests for spatial autocorrelation in OLS residuals

\begin{tabular}{lccc}
\hline Weight matrix & $\begin{array}{c}\text { Five nearest } \\
\text { neighbors }\end{array}$ & Inverse distance & $\begin{array}{c}\text { Squared inverse } \\
\text { distance }\end{array}$ \\
\hline $\begin{array}{l}\text { Moran's I test } \\
\text { LM lag tests }\end{array}$ & $8.43^{* * *}$ & $9.56^{* * * *}$ & $8.15^{* * *}$ \\
$-\quad$ for omitted spatial lag & $96.90^{* * *}$ & $106.16^{* * * *}$ & $88.17^{* * *}$ \\
$-\quad$ for omitted spatial error & $60.62^{* * *}$ & $73.43^{* * *}$ & $56.86^{* * *}$ \\
Robust LM lag tests & $37.59^{* * *}$ & $32.98^{* * *}$ & $31.98^{* * *}$ \\
$-\quad$ for omitted spatial lag & 1.31 & 0.25 & 0.67 \\
\hline$\quad$ for omitted spatial error & & & \\
\hline
\end{tabular}

Notes: The Moran I statistic follows a standard normal distribution. The LM test statistics are $\chi^{2}-$ distributed with one degree of freedom. 
Table 3: Results

(1)

(2)

(3)

(4)

\begin{tabular}{|c|c|c|c|c|}
\hline Model & SAR & GSM & SAR & SAR Tobit \\
\hline Estimation method & ML & ML & ML & $\begin{array}{l}\text { Bayesian } \\
\text { MCMC }\end{array}$ \\
\hline Weight matrix & \multicolumn{4}{|c|}{ Five nearest neighbors } \\
\hline Constant & $\begin{array}{l}-0.287 \\
(-0.54)\end{array}$ & $\begin{array}{l}-0.142 \\
(-0.30)\end{array}$ & $\begin{array}{c}-1.248 * * \\
(-2.04)\end{array}$ & $\begin{array}{c}-1.545^{*} \\
(-1.88)\end{array}$ \\
\hline Income & $\begin{array}{c}0.052 * * * \\
(3.49)\end{array}$ & $\begin{array}{c}0.050 * * * \\
(3.40)\end{array}$ & $\begin{array}{c}0.050 * * * \\
(3.37)\end{array}$ & $\begin{array}{c}0.049 * * \\
(2.40)\end{array}$ \\
\hline Lagged income & $\begin{array}{l}0.028 \\
(1.59)\end{array}$ & $\begin{array}{l}0.021 \\
(1.18)\end{array}$ & $\begin{array}{c}0.047 * * \\
(2.53)\end{array}$ & $\begin{array}{c}0.057 * * \\
(2.33)\end{array}$ \\
\hline Homeownership rate & $\begin{array}{c}-0.016^{* *} \\
(-2.45)\end{array}$ & $\begin{array}{c}-0.016 * * * \\
(-2.68)\end{array}$ & $\begin{array}{l}-0.010 \\
(-1.32)\end{array}$ & $\begin{array}{l}-0.009 \\
(-0.90)\end{array}$ \\
\hline Landlord lobby & $\begin{array}{c}0.259 * * \\
(2.18)\end{array}$ & $\begin{array}{c}0.212 * * \\
(1.99)\end{array}$ & $\begin{array}{l}0.231^{*} \\
(1.96)\end{array}$ & $\begin{array}{c}0.264 * \\
(1.78)\end{array}$ \\
\hline Landowner lobby & $\begin{array}{c}-0.063 * * * \\
(-4.11)\end{array}$ & $\begin{array}{c}-0.053 * * * \\
(-3.68)\end{array}$ & $\begin{array}{c}-0.058 * * * \\
(-3.75)\end{array}$ & $\begin{array}{c}-0.105 * * * \\
(-4.26)\end{array}$ \\
\hline $\begin{array}{l}\text { Construction lobby } \\
\text { ("growth machine") }\end{array}$ & $\begin{array}{l}0.007 \\
(0.60)\end{array}$ & $\begin{array}{l}0.007 \\
(0.65)\end{array}$ & $\begin{array}{l}0.008 \\
(0.71)\end{array}$ & $\begin{array}{l}0.002 \\
(0.12)\end{array}$ \\
\hline Population density & & & $\begin{array}{c}0.021 * * * \\
(3.02)\end{array}$ & $\begin{array}{c}0.019 * * \\
(2.13)\end{array}$ \\
\hline Public debt & & & $\begin{array}{l}-0.004 \\
(-0.35)\end{array}$ & $\begin{array}{l}-0.004 \\
(-0.25)\end{array}$ \\
\hline Population growth & & & $\begin{array}{l}0.010 \\
(1.40)\end{array}$ & $\begin{array}{c}0.018 * * \\
(-0.25)\end{array}$ \\
\hline Rho & $\begin{array}{c}0.555^{* * * *} \\
(10.15)\end{array}$ & $\begin{array}{l}0.625^{* * * *} \\
(9.70)\end{array}$ & $\begin{array}{l}0.491 * * * \\
(8.28)\end{array}$ & $\begin{array}{l}0.487 * * * \\
(7.59)\end{array}$ \\
\hline Lambda & & $\begin{array}{l}-0.160 \\
(-1.55)\end{array}$ & & \\
\hline Log-likelihood & -302.590 & -301.75 & -297.437 & \\
\hline AIC & 2.113 & 2.108 & 2.099 & \\
\hline $\mathrm{BIC}$ & 2.201 & 2.195 & 2.224 & \\
\hline Pseudo- $\mathrm{R}^{2}$ & 0.701 & 0.765 & 0.728 & 0.702 \\
\hline
\end{tabular}

Notes: t-values are in parentheses. Asterisks indicate significance at the $10 \%(*), 5 \%(* *)$ or $1 \%(* * *)$ level. AIC is the Akaike information criterion. BIC is the Schwarz information criterion. Pseudo $-\mathrm{R}^{2}$ is the linear correlation coefficient between the observed explained variable and the estimated explained variable. In order to avoid identification problems, the estimation of the general spatial model (column 2) was carried out using the fivenearest-neighbors matrix for the spatially lagged dependent variable and the three-nearest-neighbors matrix for the spatially correlated error terms. The estimation of the Bayesian Tobit model (column 4) is based on 10,000 draws of which 1,000 were omitted. 
Table 4: Results (alternative weight matrices)

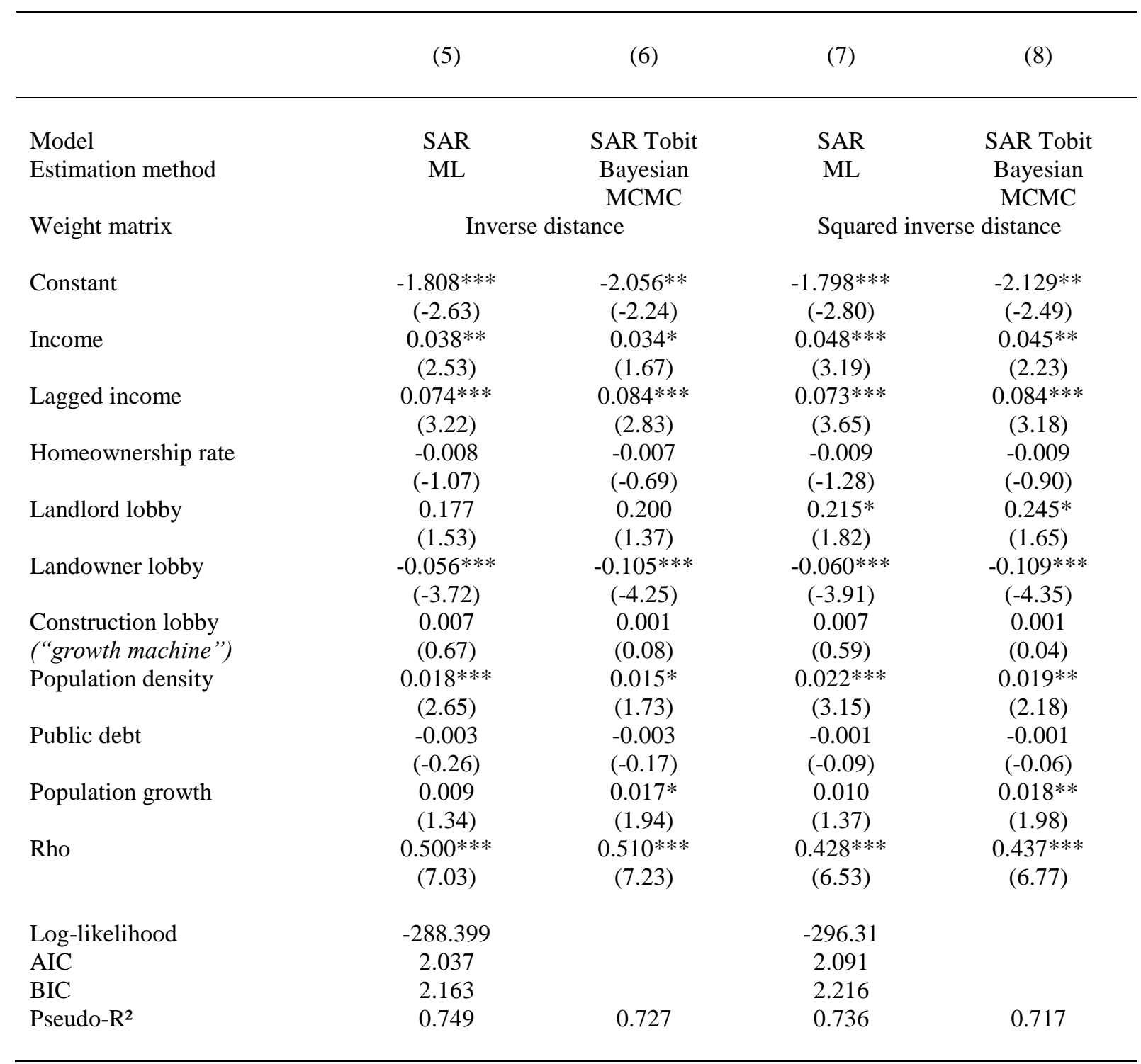

Notes: (see the notes for Table 3) 